\title{
KEYAKINAN KESEHATAN DAN PERMASALAHAN PADA PASIEN DIABETES MELITUS DI KOTA BANDUNG
}

\author{
Citra Windani Mambang Sari ${ }^{1}$, Ahmad Yamin ${ }^{1}$ \\ 1 Staf Pengajar Departemen Keperawatan Komunitas Fakultas Keperawatan Universitas Padjadjaran. \\ Email : ners_citra@yahoo.com, citra.windani@unpad.ac.id
}

\begin{abstract}
ABSTRAK
Diabetes mellitus adalah salah satu peningkatan jumlah penyakit kronis di dunia. Provinsi Jawa Barat juga memiliki prevalensi peningkatan 1,4\% di tahun 2007 menjadi 2\% pada tahun 2013 dan memiliki jumlah penderita paling banyak yang merasakan gejala diabetes melitus, namun belum pernah diteliti yaitu sekitar 225 ribu orang (Riskesdas, 2013). Pasien Diabetes Mellitus berisiko mengalami komplikasi makrovaskular dan mikrovaskuler yang dapat menurunkan kualitas hidup. Upaya pencegahan dari komplikasi dapat dilihat dari kebutuhan perawatan yang diharapkan pasien Diabetes Mellitus dengan mengidentifikasi keyakinan kesehatan dan permasalahan dari sisi pasien. Tujuan dari penelitian ini adalah untuk mengidentifikasi keyakinan kesehatan dan permasalahan pasien Diabetes Mellitus di kota Bandung. Responden penelitian adalah 121 pasien Diabetes Melitus di kota Bandung yang diambil dengan cara purposive dari 10 Prolanis tertinggi di kota Bandung. Metode penelitian yang digunakan adalah metode kuantitatif dengan menggunakan 4 kuesioner yaitu karakteristik kesehatan, pengetahuan tentang Diabetes Mellitus, keyakinan kesehatan, permasalahan kesehatan pada pasien Diabetes Melitus. Kuesioner yang digunakan berdasarkan penelitian dan dianalisis dengan statistic deskriptif. Hasil penelitian adalah pengetahuan $(\mathrm{M}=14,65, \mathrm{SD}=13,35)$, keyakinan kesehatan tentang Diabetes Mellitus $(\mathrm{M}=71,79, \mathrm{SD}=10,14)$, permasalahan pada Diabetes $(\mathrm{M}=43,54, \mathrm{SD}=13,35)$. Temuan dari penilaian kebutuhan ini mengarah pada perencanaan dan penyampaian program komprehensif dan terintegrasi bagi pasien dengan Diabetes.
\end{abstract}

Kata Kunci : Diabetes mellitus, keyakinan kesehatan, pengetahuan, permasalahan

\begin{abstract}
Diabetes mellitus is one of an increasing number of chronic diseases in the world. West Java province also has an increased prevalence of $1.4 \%$ in 2007 to $2 \%$ in 2013 and has one of the most sufferers feel the symptoms of diabetes mellitus, but have never researched which is about 225 thousand people. Patients at risk of Diabetes Mellitus undergoing microvascular complications and makrovaskular that can degrade the quality of life. Prevention efforts of the complications can be seen from the expected care needs of patients with Diabetes Mellitus health beliefs and identify problems from the patient's side.The purpose of this research is to identify the health beliefs and problems of the patients of Diabetes Mellitus in Bandung.The respondents of the research was 121 patients of Diabetes mellitus in Bandung were taken with purposive way of 10 highest Prolanis in Bandung. The research method used is the quantitative method by using 4 questionnaire health characteristics, knowledge of Diabetes Mellitus, health beliefs, health problems in patients of Diabetes mellitus.Questionnaires that are used based on research and analyzed with descriptive statistics. The research is knowledge $(M=14.65, S D=$ 13.35), health beliefs about Diabetes Mellitus $(M=71.79, S D=10,14)$, problems in Diabetes $(M=43.54, S D$ $=13,35)$. The findings of this needs assessment lead to the planning and delivery of comprehensive and integrated program for patients with Diabetes.
\end{abstract}

keywords : Diabetes mellitus, health Belief, health problems, knowledge 


\section{PENDAHULUAN}

Meningkatnya mortalitas dan morbiditas penyakit tidak menular termasuk penyakit kronis dan kanker menjadi perhatian global dewasa ini. Menurut World Health Organization (WHO, 2014), sebanyak $66 \%$ orang di dunia meninggal karena noncommunicable diseases. Orang dewasa yang meninggal dan membutuhkan perawatan paliatif berasal dari penyakit kardiovaskuler $(38,5 \%)$, Kanker (34 \%), penyakit pernafasan kronis $(10,3 \%)$ dan Diabetes Melitus (4,5\%) (WHO, 2014). Menurut hasil Riskesdas (2013) prevalensi Diabetes Melitus di Indonesia adalah 2,1, dan di Jawa Barat sebesar 2,0. Prevalensi Diabetes Melitus di perkotaan cenderung lebih tinggi dibanding di perdesaan. Angka tersebut merupakan angka yang cukup serius dan memerlukan perhatian khusus.

Berdasarkan WHO (2002), perawatan pasien Diabetes Melitus seharusnya integrasi secara holistik dan diberikan oleh dengan pendekatan multidisplin ke pasien dan keluarganya. Menurut Strong et al (2012), anggota multidisplin meliputi perawat, fisioterapis, terapis okupasi, dokter dan pekerja sosial. Perawatan yang dapat diberikan adalah perawatan paliatif yaitu dengan pendekatan yang meningkatkan kualitas hidup pasien dan keluarga, melalui pencegahan dengan identifikasi dini dan pengkajian serta penanganan nyeri dan masalah lainnya, fisik, psikososial dan spiritual (WHO, 2014). Menurut Bartley et al (2015), pasien dan keluarga dengan kebutuhan perawatan paliatif seharusnya diberikan perawatan yang sesuai dengan kebutuhan menggunakan pendekatan holistik, fleksibel dan berfokus pada pasien.

Beberapa penelitian perawatan paliatif di komunitas telah dilakukan. Dongre et al (2012) mengevaluasi pengaruh dari perawatan paliatif community-managed di Tamil Nadu terhadap kualitas hidup dari 450 lansia. Hasil penelitian dari Dongre et al (2102) menyimpulkan bahwa kualitas hidup secara fisik dan psikososial meningkat signifikan dibanding kelompok kontrol.

Model penanganan komprehensif telah dilakukan oleh Keogh et al (1999) dengan melaksanakan 141 pertemuan yang terdiri dari multidisiplin yaitu perawat, fisioterapis, dokter, psikolog, pekerja sosial, dan terapis okupasi. Setiap sesi dihadiri setidaknya dua edukator dari disiplin tenaga kesehatan yang berbeda. Metode yang dilakukan menggunakan kelompok kerja kecil, studi kasus, pemutaran video, mini-lectures, pemutaran musik dan bermain peran. Hasil dari penelitian ini adalah meningkatkan keterampilan komunikasi, mengontrol symptom pada penyakit. Hal ini sesuai dengan Korf et al (1997) menyatakan bahwa hubungan kolaborasi yang efektif antar tenaga kesehatan menjadikan pasien dan keluarga dapat menyelesaikan tugas perawatan. Penelitian Seow et al (2014) juga menyimpulkan bahwa tim perawatan paliatif berbasis masyarakat efektif menurunkan perawatan akut dan kematian di rumah sakit.

Saat ini, perawatan Diabetes Melitus di Indonesia masih terpusat di Rumah Sakit dan belum ada pengembangan ke tingkat pelayanan kesehatan primer. Penelitian tentang kebutuhan perawatan pasien Diabetes Melitus di Rumah Sakit sudah ada secara terintegrasi dengan berbagai tenaga kesehatan, padahal saat tindak lanjut perawatan di rumah dan masyarakat sangat diperlukan. Saat ini, kajian kebutuhan perawatan integratif pasien Diabetes Melitus di masyarakat belum pernah diteliti. Dengan mempertimbangkan belum adanya model perawatan yang komprehensif pada penyakit Diabetes Melitus di masyarakat, maka perlu di kaji kebutuhan perawatan integrative dan dibuat suatu model perawatan integratif untuk pasien dengan penyakit Diabetes Melitus. Perawatan integratif pada pasien Diabetes Melitus di masyarakat yang melibatkan multi disiplin berbasis masyarakat dan berfokus pada pasien dan keluarga. Hasil penelitian ini diekspektasi dapat memberikan kebutuhan berbasis bukti yang berasal dari berbagai pihak tentang kajian kebutuhan perawatan intergratif Diabetes Melitus di masyarakat di Indonesia. Tujuan penelitian adalah mengidentifikasi kebutuhan perawatan integratif penyakit Diabetes Melitus di masyarakat dengan tujuan khusu mengidentifikasi kajian kebutuhan perawatan penyakit Diabetes Melitus di masyarakat dan mengidentifikasi kajian kebutuhan perawatan integrative pada pasien diabetes di masyarakat. 


\section{METODE PENELITIAN}

Penelitian ini dilakukan dalam dua tahap yaitu tahap pertama (tahun kesatu) adalah tahap mengkaji kebutuhan perawatan integratif di masyarakat dari pasien dan keluarga, multidisiplin dan

stake holder. Tahap ini menggunakan metode deskriptif kuantitatif dan kualitatif. Metode deskriptif kuantitatif dengan menggunakan kuesioner tertutup dengan data yang ditargetkan adalah demografi, penyakit kronis yang paling banyak, data keluhan keluhan yang muncul, kebutuhan keluarga. Tahap ini pasien dikaji dengan menggunakan dengan 4 kuesioner adalah demografi, pengetahuan, keyakinan dan permasalahan tentang DM yang sudah diadopsi dari penelitian Hall (2013) dan sudah diuji validitas dan reliabilitasnya melalui back translation. Analisis data kuantitatif dianalisis dan digambarkan melalui frekuensi, persentase, mean, dan standar deviasi (atau median dan quartile deviasi).

\section{HASIL}

Tabel 1 Karakteristik umum dan karakteristik kesehatan responden DM (N=121)

\begin{tabular}{|c|c|c|c|}
\hline \multicolumn{2}{|c|}{ Variabel } & $\mathbf{N}$ & $\%$ \\
\hline \multirow[t]{8}{*}{ Usia } & $37-42$ tahun & 1 & 0.8 \\
\hline & 43-48 tahun & 6 & 5 \\
\hline & 49-54 tahun & 15 & 12.4 \\
\hline & 55-60 tahun & 35 & 28.9 \\
\hline & $61-60$ tahun & 29 & 24 \\
\hline & $67-72$ tahun & 20 & 16.5 \\
\hline & $73-78$ tahun & 12 & 9.9 \\
\hline & 79-84 tahun & 3 & 2.5 \\
\hline \multirow[t]{2}{*}{ Jenis Kelamin } & Laki-laki & 21 & 17.4 \\
\hline & perempuan & 100 & 82.6 \\
\hline \multirow[t]{4}{*}{ Status perkawinan } & Belum menikah & 10 & 8.3 \\
\hline & Menikah & 81 & 66.9 \\
\hline & Bercerai & 3 & 2.5 \\
\hline & Janda/duda & 27 & 22.3 \\
\hline \multirow[t]{4}{*}{ Agama } & Islam & 109 & 90.1 \\
\hline & Kristen & 6 & 5 \\
\hline & Katolik & 3 & 2.5 \\
\hline & Budha & 3 & 2.5 \\
\hline \multirow[t]{6}{*}{ Suku } & Sunda & 95 & 78.5 \\
\hline & Jawa & 13 & 10.7 \\
\hline & Minang & 1 & 0.8 \\
\hline & Batak & 4 & 3.2 \\
\hline & Chinese & 3 & 2.5 \\
\hline & Lainnya & 5 & 4.1 \\
\hline \multirow[t]{5}{*}{ Pekerjaan } & Tidak bekerja & 99 & 81.8 \\
\hline & Buruh & 4 & 3.3 \\
\hline & PNS & 3 & 3.5 \\
\hline & Pegawai swasta & 3 & 2.5 \\
\hline & wiraswasta & 10 & 8.3 \\
\hline \multirow[t]{5}{*}{ Pendidikan } & Tidak sekolah & 5 & 4.1 \\
\hline & SD & 36 & 29.8 \\
\hline & SLTP & 22 & 18.2 \\
\hline & SLTA & 42 & 34.7 \\
\hline & Universitas & 16 & 13.2 \\
\hline \multirow[t]{2}{*}{ Lama menderita DM } & $<3$ tahun & 40 & 33.1 \\
\hline & $>3$ tahun & 81 & 66.9 \\
\hline \multirow[t]{2}{*}{ Riwayat merokok } & Tidak pernah & 92 & 76 \\
\hline & Pernah tapi sudah & 26 & 21.5 \\
\hline
\end{tabular}




\begin{tabular}{|c|c|c|c|}
\hline \multicolumn{2}{|c|}{ Variabel } & \multirow[t]{2}{*}{$\mathbf{N}$} & \multirow[t]{2}{*}{$\%$} \\
\hline & berhenti & & \\
\hline & Masih merokok & 3 & 2.5 \\
\hline \multirow[t]{3}{*}{ Riwayat minum alcohol } & Tidak pernah & 116 & 95.9 \\
\hline & $\begin{array}{l}\text { Pernah tapi sudah } \\
\text { berhenti }\end{array}$ & 4 & 3.3 \\
\hline & Masih minum & 1 & 0.8 \\
\hline \multirow[t]{3}{*}{ Aktivitas rutin } & Bekerja & 23 & 19 \\
\hline & IRT & 91 & 75.2 \\
\hline & Lain-lain & 7 & 5.8 \\
\hline \multirow[t]{5}{*}{ Jenis Olahraga } & Tidak pernah & 12 & 9.9 \\
\hline & Berjalan & 59 & 48.8 \\
\hline & Lari & 5 & 4.1 \\
\hline & Senam & 40 & 33.1 \\
\hline & bersepeda & 5 & 4.1 \\
\hline \multirow[t]{2}{*}{ Diet teratur } & $\mathrm{Ya}$ & 68 & 56.2 \\
\hline & Tidak & 51 & 43.7 \\
\hline \multirow[t]{2}{*}{ Keluhan sakit kepala } & $\mathrm{Ya}$ & 12 & 9.9 \\
\hline & Tidak & 109 & 90.1 \\
\hline \multirow[t]{2}{*}{ Keluhan kaki } & $\mathrm{Ya}$ & 75 & 62 \\
\hline & Tidak & 46 & 38 \\
\hline \multirow[t]{2}{*}{ Penyakit comorbid } & $\mathrm{Ya}$ & 76 & 62.8 \\
\hline & Tidak & 45 & 37.2 \\
\hline \multirow[t]{5}{*}{ IMT } & Kurus tingkat berat & 1 & 0.8 \\
\hline & Kurus tingkat ringan & 2 & 1.7 \\
\hline & Normal & 57 & 47.1 \\
\hline & Obesitas tingkat ringan & 24 & 19.8 \\
\hline & Obesitas tingkat berat & 37 & 20.6 \\
\hline
\end{tabular}

Dari hasil tabel 1 menggambarkan karakteristik umum dan karakteristik kesehatan dari responden. Hampir sebagian $(28,9 \%)$ dari responden berusia pra lansia yakni dari 55-60 tahun. Hampir seluruh reponden $(82.6 \%)$ adalah wanita dan status menikah (66,9\%). Hampir seluruhnya adalah beragama islam $(90,1 \%)$ dan sebagian besar responden berasal dari suku Sunda (78,5\%). Hampir sebagian dari responden mempunyai latar belakang pendidikan dari SLTA $(34,7 \%)$. Sebagian besar $(66,9 \%)$ dari responden telah lama didiagnosa DM lebih dari 3 tahun. Sebagian besar responden tidak pernah merokok $(92 \%$ dan tidak pernah meminum alcohol $(95,9 \%)$. Sebagian besar dari responden adalah ibu rumah tangga $(75,2 \%)$. Olahraga yang biasa dilakukan oleh reponden adalah berjalan $(48,8 \%)$. Sebagian besar dari responden $(56,2 \%)$ menjalankan diet teratur. Hampir seluruhnya dari responden tidak mengalami keluhan sakit kepala $(90,1 \%)$. Sebagian dari responden $(62 \%)$ mengalami keluhan kaki seperti baaal dan neuropati dan juga memiliki penyakit selain dari DM $(62,8 \%)$. Hampir sebagian besar dari responden mempunyai IMT normal $(47,1 \%)$.

Tabel 5 Hasil uji deskriptif pada variabel pengetahuan, permasalahan dan keyakinan pada pasien DM $(n=121)$

\begin{tabular}{|c|c|c|c|c|}
\hline \multirow[t]{2}{*}{ Variabel } & \multicolumn{2}{|c|}{ Dibawah rata-rata } & \multicolumn{2}{|c|}{ Di atas rata-rata } \\
\hline & $\mathrm{N}$ & Persentase & $\mathrm{N}$ & Persentase \\
\hline Pengetahuan & 54 & 44.6 & 66 & 54.5 \\
\hline Permasalahan & 62 & 51.2 & 58 & 47.9 \\
\hline Keyakinan & 51 & 42.1 & 70 & 57.9 \\
\hline
\end{tabular}


Dari hasil tabel 5, menggambarkan bahwa sebagian besar pengetahuan responden adalah diatas rata-rata kelompok $(M=14,65$, SD 2,5). Permasalahan DM dirasakan oleh sebagian besar $\operatorname{responden}(\mathrm{M}=43.54, \mathrm{SD}=13.35)$. Sebagian besar keyakinan tentang DM diatas rata-rata $(M=71.79, S D=10.14)$.

Tabel 6 hasil uji silang variabel karateristik umum dan kesehatan dengan pengetahuan pasien DM $(\mathbf{n}=121)$

\begin{tabular}{|l|l|r|r|r|r|}
\hline \multicolumn{2}{|c|}{ VARIABEL } & \multicolumn{2}{c|}{ Dibawah rata-rata } & \multicolumn{2}{c|}{ Diatas rata-rata } \\
\cline { 3 - 6 } \multicolumn{2}{|c|}{ Pendidikan } & N & $\%$ & N & $\%$ \\
\cline { 2 - 6 } & Sidak Sekolah & 4 & 7.4 & 1 & 1.5 \\
\cline { 2 - 6 } & SD & 24 & 44.4 & 12 & 18.2 \\
\cline { 2 - 6 } & SLTP & 6 & 11,1 & 15 & 22,7 \\
\cline { 2 - 6 } & SLTA & 14 & 25.9 & 28 & 42.4 \\
\cline { 2 - 6 } & Universitas & 6 & 11.1 & 10 & 15.2 \\
\hline \multirow{3}{*}{$\begin{array}{l}\text { Jenis Kelamin } \\
\text { lama } \\
\text { menderita DM }\end{array}$} & Laki-laki & 9 & 16.7 & 12 & 18.2 \\
\cline { 2 - 6 } & Perempuan & 45 & 83.3 & 54 & 81.8 \\
\cline { 2 - 6 } & > 3TAHUN & 20 & 37 & 20 & 30.3 \\
\hline
\end{tabular}

Tabel 7 hasil uji silang karakteristik umum dan karakteristik kesehatan dengan permasalahan yang dirasakan pada pasien DM $(n=121)$

\begin{tabular}{|c|c|c|c|c|c|}
\hline \multicolumn{2}{|c|}{ Variabel } & \multicolumn{2}{c|}{ Di bawah rata-rata } & \multicolumn{2}{c|}{ Di atas rata-rata } \\
\cline { 3 - 6 } & N & Persentase & N & Persentase \\
\hline \multirow{3}{*}{ Pendidikan } & Tidak sekolah & 2 & 3.2 & 3 & 5.2 \\
\cline { 2 - 6 } & SD & 18 & 29 & 17 & 29.3 \\
\cline { 2 - 6 } & SLTP & 9 & 14.5 & 13 & 22.4 \\
\cline { 2 - 6 } & SLTA & 21 & 33.9 & 21 & 36.2 \\
\cline { 2 - 6 } & Universitas & 12 & 19.4 & 4 & 6.9 \\
\hline \multirow{3}{*}{$\begin{array}{c}\text { Jenis } \\
\text { Kelamin }\end{array}$} & Laki-laki & 17 & 27.4 & 4 & 6.9 \\
\cline { 2 - 6 } $\begin{array}{c}\text { Lama } \\
\text { diabetes }\end{array}$ & Perempuan & 45 & 72.6 & 54 & 93.1 \\
\cline { 2 - 6 } & $<3$ tahun & 19 & 30.6 & 21 & 36.2 \\
\hline \multirow{2}{*}{} & $>3 t a h u n$ & 43 & 69.4 & 37 & 63.8 \\
\hline
\end{tabular}

Tabel 8 hasil uji silang karakteristik umum dan karakteristik kesehatan dengan keyakinan yang dirasakan pada pasien DM $(n=121)$

\begin{tabular}{|c|c|c|c|c|c|}
\hline \multicolumn{2}{|c|}{ Variabel } & \multicolumn{2}{|c|}{ Di bawah rata-rata } & \multicolumn{2}{|c|}{ Di atas rata-rata } \\
\hline & & $\mathrm{N}$ & Persentase & $\mathrm{N}$ & Persentase \\
\hline \multirow[t]{5}{*}{ Pendidikan } & $\begin{array}{c}\text { Tidak } \\
\text { sekolah }\end{array}$ & 3 & 5.9 & 2 & 2.9 \\
\hline & SD & 18 & 35.3 & 18 & 25.7 \\
\hline & SLTP & 13 & 25.5 & 9 & 12.9 \\
\hline & SLTA & 12 & 23.5 & 30 & 42.9 \\
\hline & Universitas & 2 & 9.8 & 11 & 15.7 \\
\hline \multirow{2}{*}{$\begin{array}{c}\text { Jenis } \\
\text { Kelamin }\end{array}$} & Laki-laki & 8 & 15.7 & 13 & 18.6 \\
\hline & Perempuan & 43 & 84.3 & 57 & 81.4 \\
\hline \multirow{2}{*}{$\begin{array}{c}\text { Lama } \\
\text { diabetes }\end{array}$} & $<3$ tahun & 16 & 31.4 & 24 & 34.3 \\
\hline & $>3$ tahun & 35 & 68.6 & 46 & 65.7 \\
\hline
\end{tabular}

Dari hasil tabel 6-8 menggambarkan hasil uji silang karakteristik umum yaitu pendidikan dan jenis kelamin dengan variabel pengetahuan, permasalahan dan keyakinan responden tentang DM. Dari tabel 6, hampir sebagian besar pengetahuan diatas rata-rata pada latar belakang pendidikan SLTA, jenis kelamin perempuan dan lama DM diatas 3 tahun. Dari tabel 7, hampir sebagian besar 
permasalahan di atas rata-rata pada latar belakang pendidikan dan permpuan. Hanya saja lama sebagian besar dari responden menderita DM lebih dari 3 tahun, mempunyai permasalahan yang di bawah rata-rata. Dari tabel 8 , hampir sebagian besar keyakinan diatas rata-rata pada latar belakang pendidikan SLTA, jenis kelamin perempuan dan lama DM diatas 3 tahun.

\section{PEMBAHASAN}

Pengetahuan dari seluruh responden DM berada diatas rata-rata dengan $\mathrm{M}=14,65$, sebanyak 54,5\%. Hal ini masih dibawah dari penelitian Hall et al (2016). Dari tabel 2 menggambarkan ada pernyataan yang masih banyak salah pada responden. Tiga pernyataan tertinggi yang masih banyak salah adalah pernyataan 1 tentang mengonsumsi terlalu banyak gula dan makanan manis lainnya merupakan penyebab diabetes, pernyataan 17 tentang seseorang dengan diabetes harus membersihkan luka dengan betadine dan alcohol, pernyataan 10 tentang Olahraga teratur akan meningkatkan kebutuhan akan insulin atau obat diabetes lainnya. Dari hasil tersebut, masih banyak rentang antara pengetahuan yang harusnya dimiliki oleh pasien tentang DM dan perawatan dirinya seperti diet dan olahraga. Menurut penelitian (Barthemelow dalam Hall, 2016), pengetahuan tidak berarti merubah dari perilaku kesehatan. Hal ini juga hampir sama ditemukan dalam penelitian kualitatif, bahwa pengetahuan pada pasien masih kurang. Pengetahuan yang kurang dapat dikarenakan beberapa hal yaitu latar belakang pendidikan, jenis kelamin dan lama diabetes. Dari tabel 5 digambarkan hasil silang dari variabel tersebut dengan pengetahuan. Masih ada beberapa latar belakang pendidikan yang memiliki pengetahuan di bawah rata-rata. Dari jenis kelamin, lebih banyak perempuan yang memiliki pengetahuan di bawah rata-rata. Dari lama diabetes, setengah dari responden yang memiliki lama diabetes kurang 3 tahun masih memiliki pengetahuan yang rendah tentang DM. Hal ini bisa ditujukan menjadi bagian dari intervensi program perawatan integratif pada pasien DM.

Dari tabel 3, permasalahan yang dirasakan banyak di bawah rata-rata dari keseluruhan responden dengan $\mathrm{M}=62, \mathrm{SD} 5,2$. Berbeda dengan penelitian $\mathrm{Hal}$ et al (2016), hasil permasalahan yang dirasakan pada pasien adalah merujuk pada level distress emosi yang tinggi. Dari tabel 3 menggambarkan bahwa permasalahan tentang DM yang masih dirasakan adalah tentang saya merasa bahwa diabetes saya mengaturkan hidup saya, saya khawatir tentang kadar gula darah rendah dan saya khawatir tentang masa depan dan risiko menderita masalah serius karena memiliki diabetes. Beberapa dari responden yang memiliki permasalahan yang di bawah rata-rata banyak adalah latar belakang pendidikan yang agak tinggi, dan pada jenis kelamin perempuan. Sedangkan lama diabetes, lebih dari 3 tahun pasien menderita diabetes membuat pasien merasa mempunyai permasalahan tentang DM karena banyak yang menambah kekhawatiran. Salah satu pernyataan yang tertinggi adalah khawatir diabetes menjadi pengatur dan menentukan hidup pasien. Sama dengan penelitian Hall et al (2016), responden khawatir hidup dengan diabetes. Dari tabel 4, menggambarkan keyakinan yang dirasakan oleh pasien $\mathrm{M}=71.79, \mathrm{SD}=$ 10.14. Dari tabel tersebut ada pernyataan yang menjadikan tertinggi keyakinan pada pasien adalah mengikuti diet yang disarankan (makanan diabetes) adalah sesuatu dimana seseorang harus lakukan dan tidak peduli 'seberapa sulit' ini, suami / istri saya membantu saya mengikuti diet saya (makanan diabetes, serta pernyataan jika saya mengubah "pekerjaan", akan lebih mudah untuk mengikuti diet saya (makanan diabetes). Dari hasil uji silang dengan variabel, hampir sebagian besar keyakinan diatas rata-rata pada latar belakang pendidikan SLTA, jenis kelamin perempuan dan lama DM diatas 3 tahun. Sama dengan Hall et al (2016), pernyaatan 
tentang bila mengubah pekerjaan, akan lebih mudah mengikuti diet merupakan hambatan untuk mencapai perilaku kesehatan dalam perawatan DM.

\section{SIMPULAN DAN SARAN}

Kajian kebutuhan pada pasien DM mengidentifikasi pengetahuan, permasalahan dan keyakinan yang dirasakan oleh responden. Sebagian responden memiliki pengetahuan diatas rata-rata, sedangkan sebagian responden memiliki permasalahan di bawah rata-rata, dan sebagian besar memiliki keyakinan di atas rata-rata.

\section{DAFTAR PUSTAKA}

Bartley C, Webb J, Bayly J. 2015. Multidisciplinary Approaches to Moving and Handling for formal And Informal Carers in Community Palliative Care. International Journal of Palliative Nursing 2015, Vol 21, No.1

Busse, R., \& Stahl, J. (2014). Integrated care experiences and outcomes in Germany, the Netherlands, and England. Health Affairs, 33(9), 15491558.

Clark MJ. 2008. Community Health Nursing Advocacy for People Health. Prentice Hall.

Cramm, J. M., \& Nieboer, A. P. (2012). In the Netherlands, rich interaction among professionals conducting disease management led to better chronic care. Health Affairs, 31(11), 2493-2500.

Dongre AR, Rajendran KP, Kumar S, Desmukh PR. The Effect of Community-Managed Palliative Care Program on Quality of Life in the Elderly in Rural Tamil Nadu, India. Indian Journal of Palliative Care/Sep-Dec 2012/Volume 18/Issue 3
Hall, C, Hall AB, Kok G, Mallya J, Courtright P. (2016). A needs assessment of people living with Diabetes and Diabetic Retionopathy. BMC Research Notes.

Harkness GA, DeMarco RF. 2012. Community and Public Health Nursing Evidence for Practice. Lippincott Williams \& Wilkins.

Keogh K, Jeffrey D, Flanagan S. 1999. The Palliative Care Education Group for Gloucestershire (PEGG) : an Integrated Model of Multidisciplinary Education in Palliative Care. European Journal of Cancer Care, 1999,8,44-47

Korf, M.V; Gruman, J; Schaefer, J; Curry, SJ; Michael Von Korff, ScD; Jessie,G; Wagner, EH. 1997. Collaborative Management Chronic Illness. Ann Intern Med. 1997;127(12):1097-1102. doi:10.7326/0003-4819-127-12199712150-00008

Kruis, A. L., Boland, M. R., Assendelft, W. J., Gussekloo, J., Tsiachristas, A., Stijnen, T., ... \& Chavannes, N. H. (2014). Effectiveness of integrated disease management for primary care chronic obstructive pulmonary disease patients: results of cluster randomised trial. bmj, 349, g5392.

McVey P, McKenzie H, White K. 2013. A Community-of-Care : The Integration of Palliative Approach Within Aged Care Facilities in Australia. Health an Social Care in The Community 22 (2), 197 -209

Nuño, R., Coleman, K., Bengoa, R., \& Sauto, R. (2012). Integrated care for chronic conditions: the contribution of the ICCC Framework. Health Policy, 105(1), 55-64.

Patridge AH, Seah DSE, King T, Leighl NB, Hauke R, Wollins et al. 2014. Developing Service Model That Integrates Palliative Care Trouhout Cancer Care: The Time is Now. Journal of Clinical Oncology Volume 32 Number 29 October 10 
Riset Kesehatan dasar. 2011. Badan Penelitian dan Pengembangan Kesehatan Departemen Kesehatan RI, Diambil tanggal 20 Februari 2014.

http://www.riskesdas.litbang.depkes. go.id/2010

Seow H, Brazil K, Sussman J, Pereira J, Marshal D, Austin PC, Husain A, Rangrej J, Barbera L. 2004. Impact of Community Based, Specialist Palliative Care Teams on Hospitalisations and Emergency Department Visits Late in Life and Hospital Deaths : a pooled Analysis. BMJ 2014; 348; 33496

Soegondo et al. 2006. Konsensus Pengelolaan dan Pencegahan DM Tipe 2 Di Indonesia. Jakarta : PB Perkeni
Soegondo, S dkk. 2013. Penatalaksanaan Diabetes Melitus Terpadu. Jakarta. Fakultas Kedokteran Universitas Indonesia.

Storey L, O'Donnell L, Howard A. Developing Palliative Care Practice In The Community. Nursing Standard. 17,8,40-42

Strong S, Blencowe ns, Fox $\mathrm{T}$ et al (2012). The Role of Multidisclinary Teams in Decision Making for Patients with Recurrent Malignant Disease, Palliat Med 26(7) : 95-8

WHO. 2014. Global Atlas of Palliative Care at the End of Life. Diunduh dari who 